\title{
Persistence in intra-annual snow depth distribution : 2. Fractal analysis of snow depth development
}

\author{
M. Schirmer ${ }^{1}$ and M. Lehning ${ }^{1}$ \\ Received 15 April 2010; revised 17 June 2011; accepted 29 June 2011; published 17 September 2011.
}

[1] We present an analysis of high resolution laser scanning data of snow depths of three different slopes in the Wannengrat catchment (introduced in part 1) using omnidirectional and directional variograms for three specific terrain features; cross-loaded slopes, lee slopes, and windward slopes. A break in scaling behavior was observed in all subareas, which can be seen as the roughness scale of bare earth terrain which is modified by the snow cover. In the wind-protected lee slope a different scaling behavior was observed, compared to the two wind-exposed areas. The wind-exposed areas have a smaller ordinal intercept $\gamma$, a smaller short range fractal dimension $D$, and a larger scale break distance $L$ than the wind-protected lee slope. Snow depth structure inherits characteristics of dominant NW storms, which results, e.g., in a trend toward larger break distances in the course of the accumulation season. This can be interpreted as a result of surface smoothing at increasing scales. Similar scaling characteristics were obtained for two different years at the end of the accumulation season. Since snow depth structure is altered strongly by NW storms, this inter-annual consistency may strongly depend on their frequency in an accumulation period. With the analysis of directional variograms anisotropies of fractal parameters were detected, which were related to dominant wind directions.

Citation: Schirmer, M., and M. Lehning (2011), Persistence in intra-annual snow depth distribution: 2. Fractal analysis of snow depth development, Water Resour. Res., 47, W09517, doi:10.1029/2010WR009429.

\section{Introduction}

[2] Scale issues have always been a major subject in natural sciences. The fractal concept helps to deal with scale issues and is based on observations of (statistical) scale invariance or self-similarity in nature. This concept was initially used to describe landforms by Mandelbrot [1977, 1982], and research continued as new data becomes available for a wider range of spatial scales [e.g., Abedini and Shaghaghian, 2009]. However, a consensus has emerged that natural phenomena only exhibit statistical self-similarity in limited regions and over limited ranges of scale [Xu et al., 1993; Sun et al., 2006]. Therefore, many studies used a multifractal model with at least two ranges of different scaling behaviors separated by a scale break [Sun et al., 2006]. Furthermore, the temporal development of scaling parameters could be assessed for example for seasonal changes in surface roughness due to the evolving vegetation [Pachepsky and Ritchie, 1998] or for changes in an urban heat island effect across several years and between different seasons of a year in a Chinese city [Weng, 2003].

[3] The scaling behavior of snow depth was studied with manual probing, e.g., Shook and Gray [1996], Kuchment and Gelfan [2001], and Arnold and Rees [2003], who found statistical self-similarity at least at certain scales or observed

\footnotetext{
${ }^{1}$ WSL Institute for Snow and Avalanche Research SLF, Davos, Switzerland.

Copyright 2011 by the American Geophysical Union. 0043-1397/11/2010WR009429
}

a break in scaling behavior at approximately tens of meters (break distance). An important step further was possible through high-resolution airborne laser scanning data [Deems et al., 2006; Trujillo et al., 2007]. Both studies found a multiscaling behavior with a stronger spatially correlated structure before a scale break, which was consistent with the distance found in the previous studies. In total, both studies analyzed six areas with an extent of $1 \mathrm{~km}^{2}$ each with different vegetation and relief characteristics. Both studies established a link between scaling behavior of snow depth and vegetation due to similar break distances. Trujillo et al. [2007] could group their five study areas into areas more or less dominated by wind. They noticed that in winddominated areas the scale break found in the vegetation height data were lower than in corresponding snow depth data, while it was at a similar distance in less wind-affected areas. No scale breaks were observed for the sum of vegetation height plus topography. On the contrary, Deems et al. [2006] found scale breaks in vegetation height plus topography in distances of the same magnitude as found for snow depth. However, they found no scale break for vegetation height alone. It appears that the difference in methods could be the only explanation for the disagreement since the same data sets were used. Furthermore, Deems et al. [2006] related differences in break distances between regions to overall relief, while Trujillo et al. [2007] could not detect such a dependency. In an additional study, Trujillo et al. [2009] confirmed their hypothesis of a relation between break distances and wind speeds in two adjacent subareas. Deems et al. [2006] identified a global scaling behavior in their analysis of a snow depth data. Both findings suggest 
that such "global" scaling behavior can be partitioned in a number of clusters of different self-similar scaling regions due to different processes dominating in each region. Deems et al. [2008] observed a notable inter-annual consistency in scaling behavior after two different accumulation seasons.

[4] Many studies showed that the spatial distribution of snow depth prior to melting is more important than spatial differences in melt behavior when estimating melt dynamics in the same catchment [Anderton et al., 2004; Grünewald et al., 2010]. L. Egli et al. (Dynamics of snow ablation in a small Alpine catchment observed by repeated terrestrial laser scans, submitted to Journal of Hydrological Processes, 2011). The development of the snow depth distribution throughout the season therefore appears to be an important parameter in snow hydrology, but it is currently not well known. None of above mentioned investigations looked at the temporal development of scaling characteristics of snow depth or of snow depth change caused by individual storms during an accumulation season. No research has been done in regions of rugged, unvegetated high alpine terrain.

[5] This paper explores how the interannual consistency at the end of the accumulation season compares to the observed intra-annual consistency of individual snow storms. It quantitatively extends the description presented in Schirmer et al. [2011] (hereinafter referred to as part 1). Since fractal parameters have proved to be useful for distinguishing between surfaces that have resulted from different processes [Burrough, 1993], we want to use this method not only as a description of snow depth structure, but also to relate scale, region and temporal dependent variations observed to different formation processes.

\section{Methods}

\subsection{Field Description and Data Acquisition}

[6] Snow depth was measured before and after individual storm events in alpine terrain without vegetation using a terrestrial laser scanner (LiDAR). Three slopes of $300 \mathrm{~m}$ length were investigated, which are named in this study after their typical loading behavior during dominant NW storms: windward, lee and cross loaded (Figure 1). Mott et al. [2010] analyzed wind data with additional mobile stations in our study area, which revealed a characteristic behavior for NW storms. They studied also the orientations of drift and sastrugies obtained by high resolution orthophotos, which were delivered by a terrestrial laser scanner. The dominant direction in the cross-loaded slope could be identified as northwest (Figure 1). Low wind speeds (close to measurement accuracy) and no visible drifts were obtained in the lee slope, while for the windward slope a less consistent picture can be drawn.

[7] Part 1 presents a detailed introduction to the areas and measurement methods. In summary, the data set used in this study contains the bare earth digital elevation model, nine snowfall periods including the first snowfalls in 2008/ 09 and 2009/10 as well as the snow depth at the end of the accumulation season $\left(\mathrm{HS}_{\max }\right.$ ) for 2007/08 and 2008/09. The snow depth and snow depth change data are available in a $1 \mathrm{~m}$ resolution grid. Meteorological data were available from seven weather stations in the catchment. A climatologic analysis (part 1) showed that the winter 2008/09 was characterized by exceptional large wind speeds, while the winter before was an average winter. For precipitation and a combination of precipitation and wind both winters are rather average. In Table 1 the snowfall and storm events and their meteorological characteristics are listed. Wind speeds were measured at the wind station (Figure 1). Snow fall was measured at a nearby snow station with an ultrasonic snow depth sensor by considering the snow settling with the snow cover model SNOWPACK [Lehning et al. 1999; part 1].

\subsection{Fractal Analysis}

\subsubsection{Background}

[8] "Clouds are not spheres, mountains are not cones, coastlines are not circles ..." [Mandelbrot, 1982]. Euclidean geometry is of hardly any help to describe the irregular form of natural patterns and features [Sun et al., 2006]. Instead, nature has been shown to generate structures and patterns that can be better described using the concept of scale invariance or self-similarity. For fractal objects, a relationship exists between length and measuring scale, which can be described by a power law with exponent $(1-D)$, where $D$ is the fractal (or Hausdorff-Besicovitch) dimension. A fractal is defined formally as a set for which the fractal dimension exceeds the integer dimension in Euclidean geometry [Mandelbrot, 1982]. A curve's dimension can take any noninteger value between 1 and 2, depending on the degree of irregularity of its form. Similarly, a surface's dimension may be a noninteger value between 2 and 3 [Sun et al., 2006]. An infinitely rugged surface that fills the third dimension has a limiting fractal dimension of 3 , while a perfectly smooth surface has a fractal dimension of 2 [Goodchild and Mark, 1987]. Thus, D can be used as a measure of irregularity. Typical interpretations of $D$ in the literature are given for example by Burrough [1993], who associates low $D$ values with fractals for which long-range fluctuations dominate while large $D$ values describe the dominance of short-range fluctuations. For Lam and De Cola [1993] low $D$ values characterize smooth and persistent structures, and large $D$ values rugged and antipersistent structures. Because of the quite long history of the fractal concept, review papers are available and are referred here for further reading [e.g., Xu et al., 1993; Sun et al., 2006].

\subsubsection{Estimating Fractal Parameters}

[9] Because of typical gaps in the data delivered by the terrestrial laser scanner, the variogram method was used to estimate fractal parameters, which can be applied for irregular data [e.g., Mark and Aronson, 1984; Sun et al., 2006]. The surface investigated must fulfill the conditions of a fractal Brownian surface [Xu et al., 1993]. However, researchers have suggested that if this condition is not satisfied, this method could still be used for extracting information [Sun et al., 2006]. The variogram for a parameter $z$ is given by

$$
\hat{\gamma}(h)=\frac{1}{2|N(h)|} \sum_{(i, j) \in N(h)}\left(z_{j}-z_{i}\right)^{2},
$$

where $N(h)$ is the set of point pairs $(i, j)$ in each distance class $h$ [Webster and Oliver, 2007]. Omnidirectional variograms, which include all point pairs independently of their direction, and directional variograms, which include only point pairs within a specified directional angular class, were calculated with evenly spaced distance classes after a $\log$ transformation. To obtain enough data points for 


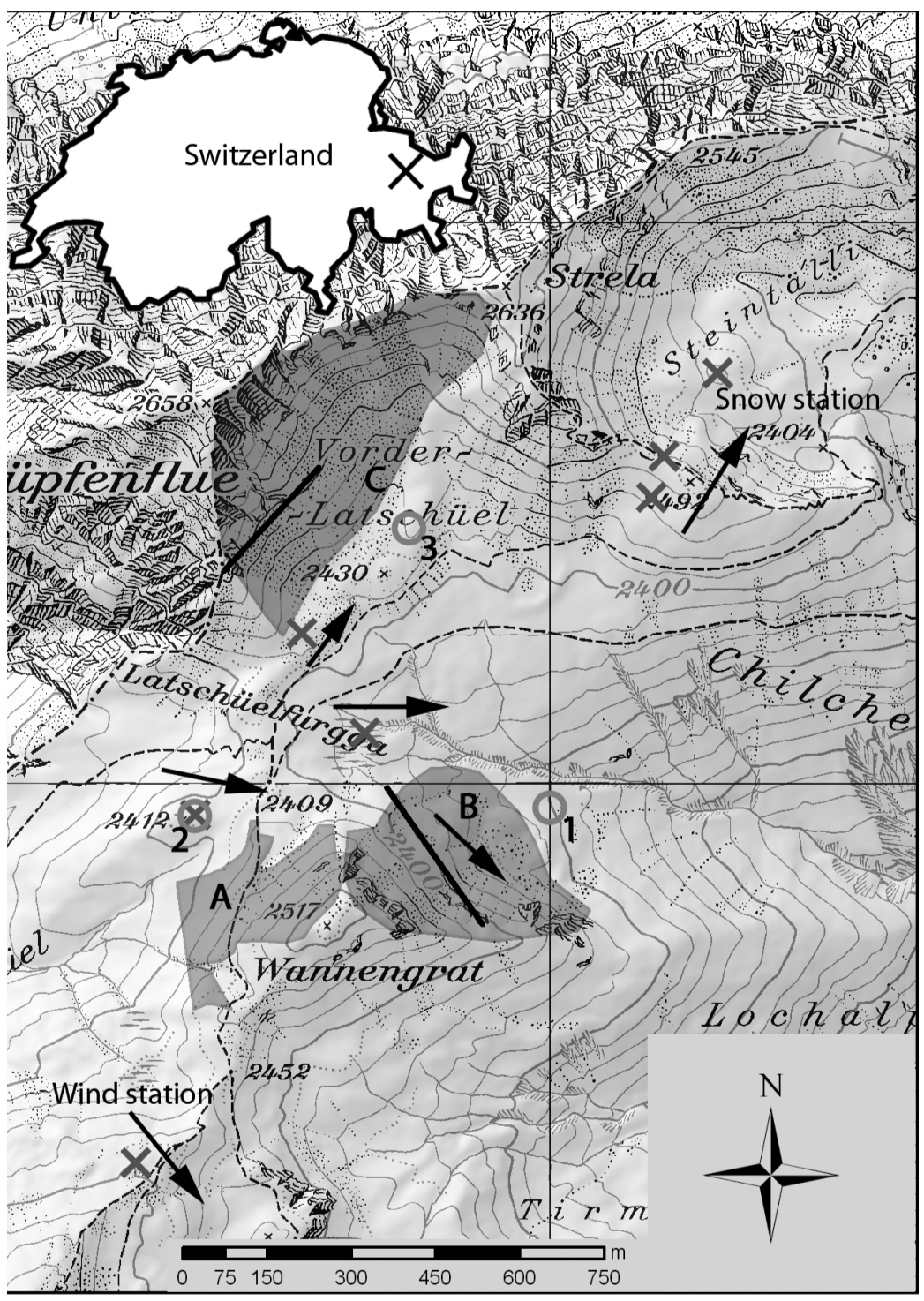

Figure 1. Overview of the study area. Shaded are the three investigated slopes: Under typical NW storms slope A is the windward slope, slope B is a cross-loaded slope, and slope C is a lee slope. The measurement positions of the terrestrial laser scanner are plotted with circles. Crosses show the position of seven weather stations. Black arrows show typical wind directions for NW storms. The direction of the arrow in the cross-loaded slope is deduced from surface structures as sastrugi and dunes. Maps reproduced with the authorization of swisstopo (JA100118).

Table 1. Meteorological Characteristics Between LiDAR Measurements

\begin{tabular}{|c|c|c|c|c|}
\hline Date & Type $^{a}$ & $v w_{\max }\left(\mathrm{m} \mathrm{s}^{-1}\right)$ & Number of Hours With $v w \geq 10 \mathrm{~m} \mathrm{~s}^{-1}$ & Precipitation $\left(\mathrm{kg} \mathrm{m}^{-2}\right)$ \\
\hline 20 Nov- 27 Nov 2008 & NW & 28 & 32 & 1.28 \\
\hline $23 \operatorname{Dec} 2008$ & $\mathrm{SE} / \mathrm{NW}$ & 21 & 19 & 1.28 \\
\hline 14 Jan 2009 & - & no data & no data & 0.13 \\
\hline 22 Jan 2009 & Hom. & no data & no data & 0.56 \\
\hline 29 Jan 2009 & SE & 13 & $<1$ & 0.26 \\
\hline 04 Feb 2009 & SE & 11 & $<1$ & 0 \\
\hline 04 Mar 2009 & NW & 23 & 19 & 1.44 \\
\hline 17 Mar 2009 & NW & 21 & 8 & 0.69 \\
\hline 27 Mar 2009 & NW & 23 & 15 & 0.64 \\
\hline
\end{tabular}

${ }^{\mathrm{a}} \mathrm{SE}$ or NW, prevailing wind directions during snowfall; Hom., homogeneous loading. 
the linear regression, 50 distance classes were chosen. The smallest distance class is given by the resolution of the grid $(1 \mathrm{~m})$. The maximum distance was chosen to be approximately half of the maximum point-pair distance in the slopes investigated [Sun et al., 2006]. This resulted in a few missing distance classes at lower distances due to the quadratic nature of the grid (e.g., Figure 2) but optimized both demands of enough data points and evenly spaced classes. Directional variograms were calculated for 16 angular classes of $22.5^{\circ}$.

[10] Since many studies reported that statistical selfsimilarity could only be observed in limited scales $[X u$ et al., 1993] and also since this was observed by all snowrelated studies mentioned in the Introduction, a multifractal model was chosen. Such multifractal behavior can be a result of variations in processes operating at different scales [e.g., Mark and Aronson, 1984]. The model given in equation (2) was fitted to the variograms solving least squares,

$$
\log (\hat{\gamma}(h))= \begin{cases}\alpha_{1} \log (h)+\beta_{1}, & \text { if } \log (h) \leq \log (L) \\ \alpha_{2} \log (h)+\beta_{2}, & \text { if } \log (h)>\log (L)\end{cases}
$$

with the continuity constraint

$$
\alpha_{1} \log (L)+\beta_{1}=\alpha_{2} \log (L)+\beta_{2} .
$$

[11] Model parameters are break distance $L$, slopes of the log-log transformed variograms $\alpha_{1}$ and $\alpha_{2}$ as well as ordinal intercepts $\beta_{1}$ and $\beta_{2}$. The slope $\alpha$ of a log-log transformed variogram is for surfaces related to the fractal dimension $D$,

$$
D_{s, l}=3-\frac{\alpha_{1,2}}{2}
$$

[12] Consistency of the fractal dimension with one's intuition about roughness was confirmed by a study of Pentland
[1984]. They used a simplified setup, however, with a constant ordinal intercept while $D$ was changing. A well-known example, where perception and fractal dimension are rather inconsistent, is mentioned by Burrough [1981]: a smooth airport runway has a relatively high $D$, since variations of long distances are low in amplitude. Similarly and more specific to snow, Fassnacht et al. [2009] obtained a large $D$ value for a snow surface previously characterized as "smooth." The corresponding roughness was objectively low in magnitude. Therefore it seems useful to refer to the magnitude of the roughness together with $D$, which is also suggested in the literature [Klinkenberg and Goodchild, 1992; Sun et al., 2006]. This magnitude can be assessed with the ordinal intercept $\left[\beta_{1}\right.$ in equation (2)] and stands for the expected differences for point pairs a unit distance apart [Klinkenberg and Goodchild, 1992]. In the literature the abbreviation $\gamma$ has been consolidated for the ordinal intercept, a notation which we choose to adopt here.

[13] A discussion on artifacts influencing $D$ is given in $X u$ et al. [1993] and Sun et al. [2006]. D is a function of methods and choice of the method's input parameters. Furthermore, smoothing effects resulting from the limited size and resolution of data will affect the estimated $D$ value. Anisotropy effects such as the distance dependent point density, footprint and accuracy of the laser scanner used in this study will certainly have an influence. We discuss these issues in section 3 .

\section{Results}

[14] The parameters discussed are the fractal dimension before and after a scale break $\left(D_{s}, D_{l}\right)$ the distance of this scale break $L$, the ordinal intercept $\gamma$, and directional anisotropies of these parameters. These fractal parameters were calculated for snow depth and snow depth change on three different slopes to study their time development in one season and the interannual comparison of $\mathrm{HS}_{\max }$ of 2 years. In

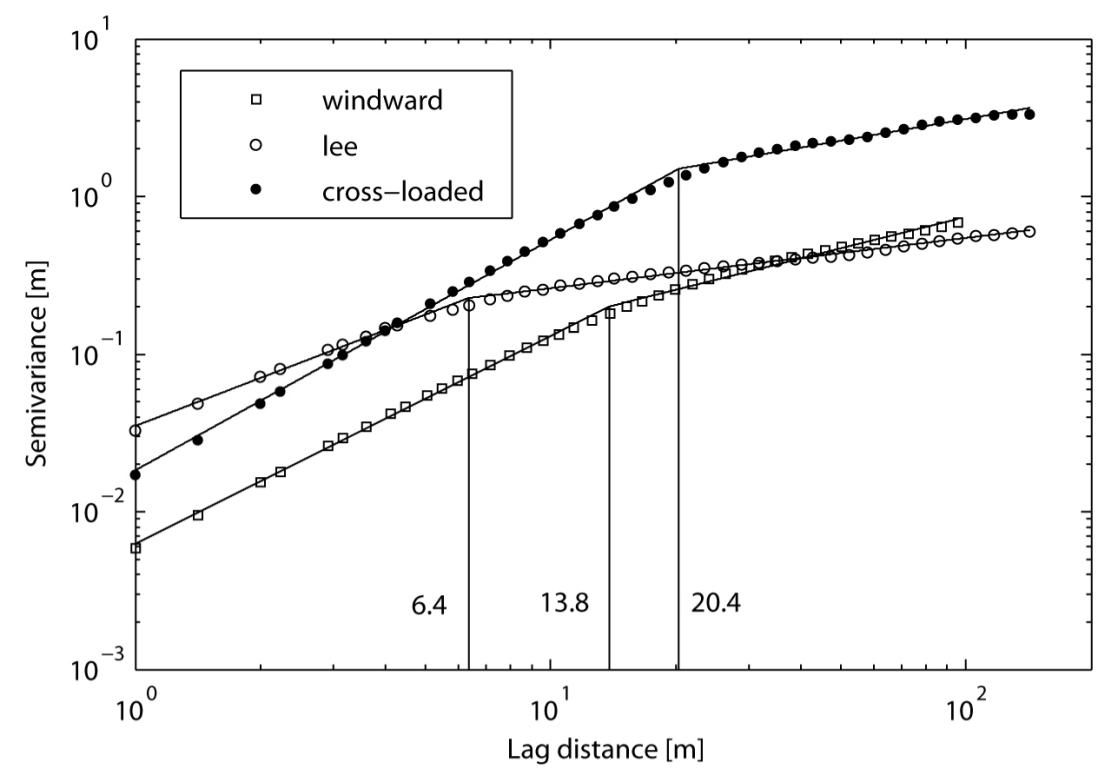

Figure 2. Omnidirectional variograms for snow depth at the end of the accumulation season 2008/09 for the three different slopes investigated. The vertical lines and corresponding numbers mark the distance of the scale breaks. 
order to structure this large parameter set, we first show results calculated with omnidirectional variograms. Snow depth structure at the end of the accumulation season, differences between slopes and similarities between two years are presented first. Subsequently, the time development of the fractal parameters $\left(D_{s}, D_{l}, L, \gamma\right)$, both calculated for snow depth and snow depth change, is presented in detail for the cross-loaded slope, with selected results from the other two types of slope. Finally, anisotropy effects are shown with directional variograms.

[15] Over 130,000 point pairs already at the smallest lag distance of one meter were available in each subregion for omnidirectional variograms, and in the same order of magnitude for directional variograms. These large number of point pairs allows reliable estimates of fractal parameters.

\subsection{Omnidirectional Variograms}

\subsubsection{Snow Depth at the End of the Accumulation} Season

[16] Variograms calculated for snow depth at the end of the accumulation season are presented in Figure 2. Scale breaks ranging between meters and tens of meters $(20 \mathrm{~m}$, cross-loaded slope) were consistently observed. Fractal dimension values before the scale break $\left(D_{s}=2.27\right.$, crossloaded slope) were lower than after the scale break indicating a more persistent structure before than after the scale break ( $D_{l}=2.77$, cross-loaded slope). This is consistent with all previous studies observing fractal behavior of snow depth as discussed in the Introduction.

[17] Region dependent variations between slopes could be detected: the lee slope was characterized by the shortest break distance $(6 \mathrm{~m})$ and larger $D$ values before $\left(D_{s}=\right.$ $2.50)$ and after the scale break $\left(D_{l}=2.84\right)$. These values indicate a structure where short-range fluctuations were dominant. The largest ordinal intercept $\gamma$ indicates that the variance at $1 \mathrm{~m}$ distance was largest. Overall variance was lowest, which was presumably responsible for our prior rating of that slope to have a more homogeneous structure (part 1). Different characteristics were observed in the cross-loaded slope. The long break distance demonstrates that the shorter, more persistent scale extends to larger distances in comparison to the lee slope. The smaller shortrange $D_{s}$ values indicate that this scale was also more spatially persistent. The intercept $\gamma$ was lower than in the lee slope, but overall variance was largest. The windward slope is characterized by a smaller variance at all scales in comparison to the cross-loaded slope.

[18] Interannual consistency in all parameters could be detected for the cross-loaded slope (Figure 3, $D_{s}=2.26, D_{l}$ $=2.79$ ). A similar consistency was observed for the lee slope, while no data in a second year was available for the windward slope. These findings confirm the large correlations mentioned above and are consistent with the study of Deems et al. [2008], who concluded that there must be interannually consistent process relationships among the major driving factors controlling snow accumulation and redistribution.

\subsubsection{Time Development in Cross-Loaded Slope}

[19] In this section we will show how this interannual consistency is formed during an accumulation season, and see if such consistent process relationships can also be observed during individual snowfall events.

\subsubsection{Changes in Snow Depth}

[20] Figure 4 shows the temporal development of shortrange fractal dimension $D_{s}$ and of break distance $L$. Most apparent is the increase in break distance for NW storms (18-37 m), especially at the end of the accumulation season (marked with arrows). These NW storms were characterized by large amounts of precipitation and wind speeds. Increasing the break distance indicates that the range of the more persistent snow depth variations was extended. We interpret this increase with successive filling of bare earth terrain depression: filling small scale terrain structure results in a somewhat smoothed surface and allows

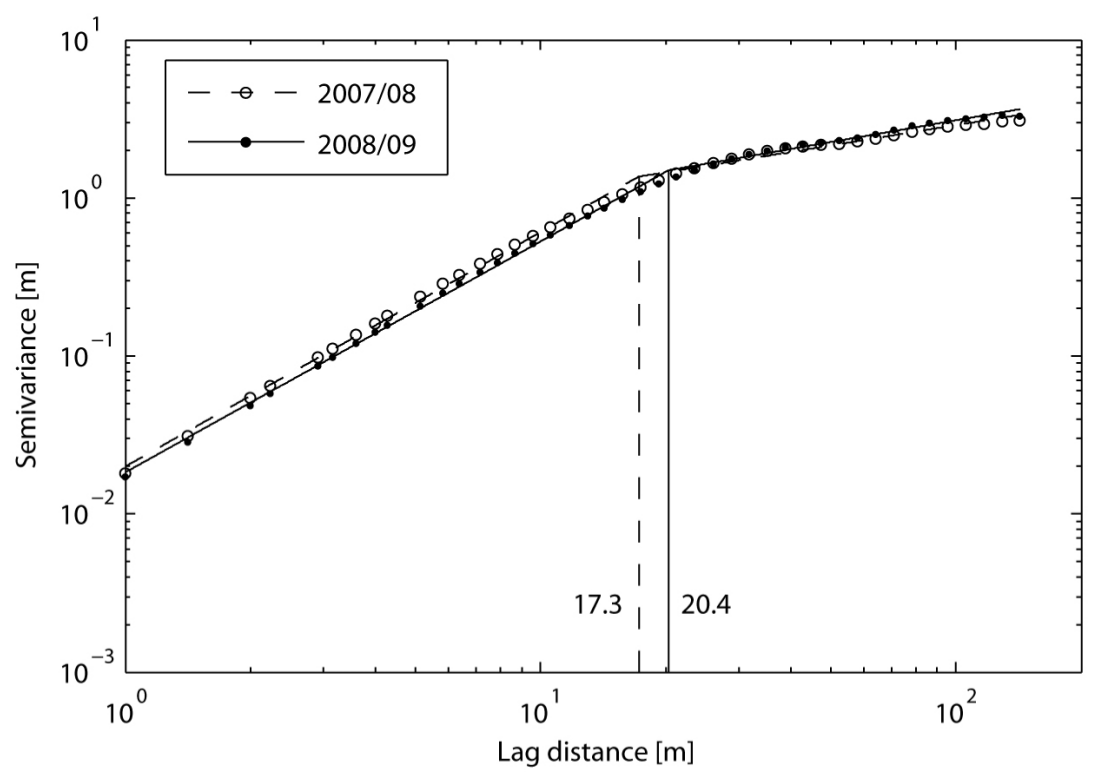

Figure 3. Omnidirectional variograms for snow depth at the end of the accumulation season in two different years in the cross-loaded slope (2008/09 same as in Figure 2). The vertical lines and corresponding numbers mark the distance of the scale breaks. 


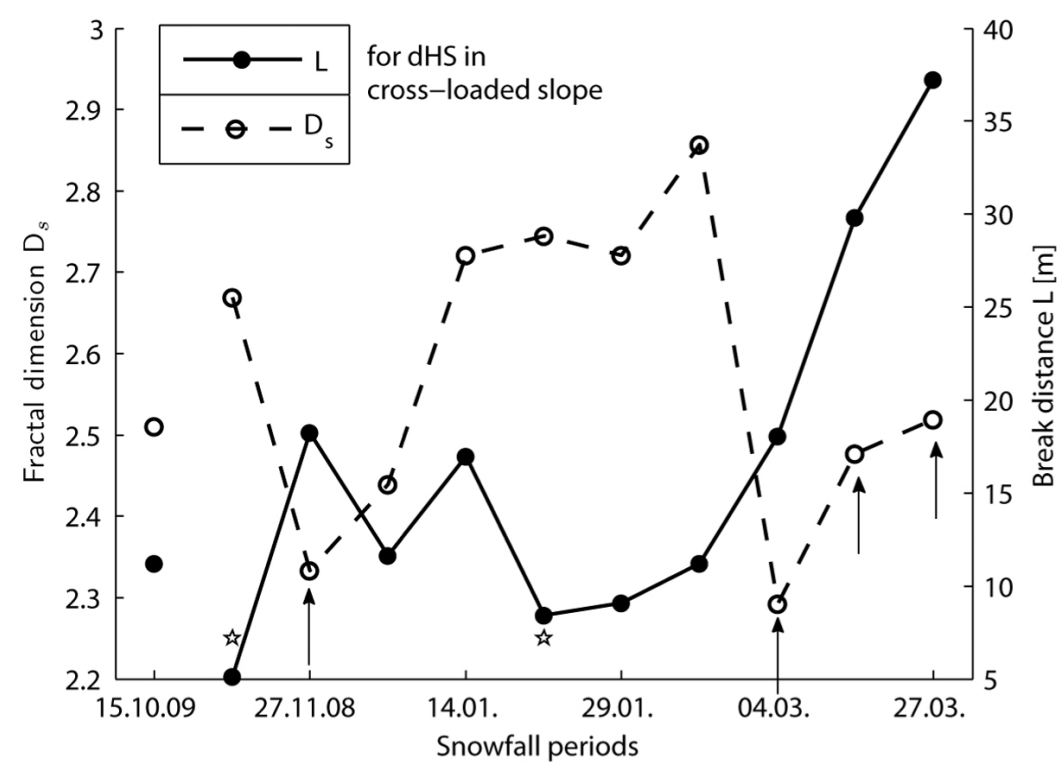

Figure 4. Temporal development of break distance $L$ and short-range fractal dimension $D_{s}$ determined for snow depth change during the winter 2008/09 in the cross-loaded slope. The values for the first snowfall in 2009/10 are plotted without connective lines. NW storms are marked with an arrow and homogeneous loading with a star.

processes such as saltation to inherit a larger process scale (see also the transect description in part 1). This increase in scale break is visible in both accumulation zones (drifts), which were observed to increase in size during all NW storms in the cross-loaded slope. Their appearance changed from a segmented structure showing various submaxima at the first NW storm (Figure 5a) into a more homogeneous structure at the last NW storm (Figure 5b).

[21] The ordinal intercept $\gamma$ (Figure 6) decreased during the accumulation season for NW storms in the cross-loaded slope. This decrease in magnitude of the roughness which was described with $D$ confirms the interpretation of bare earth terrain filling and surface smoothing at small scales. A similar decrease was observed with the overall variance (see part 1). The decrease of the overall variance can also be explained with the amount of snowfall reported at a flat field snow station during NW storms (Table 1): larger total variance might be explained with larger snowfall amount. $\gamma$ seems to show a more consistent time dependency than the overall variance. For the second NW storm, which had a large snowfall amount similar to the first NW storm, $\gamma$ was already much smaller and more similar to subsequent NW storms with lower snowfall amounts. The decrease of $\gamma$ with time confirms the hypothesis of topographic smoothing during the accumulation season: the greater the topographic smoothing, the smaller the magnitude of the short-range fluctuations of snow depth change.

[22] The fractal dimension and break distance are able to distinguish between NW storms (marked with arrows) and other periods; small $D_{s}$ values and long break distances are typical features of NW storms in the Wannengrat catchment (Figure 4). During these events, accumulation was concentrated in both accumulation drift zones. This resulted in long-range dominated fluctuations (below the scale break) and explains the low $D_{s}$ values. Also after the scale break a larger spatial persistence was observed with long-range $D_{l}$ values of approximately 2.8 while they had values around 2.95 for other periods.

[23] In comparison to the NW storms, after both homogeneous snowfalls during low wind speeds, short break distances and large $D_{s}$ values were observed (marked with stars in Figure 4). Particularly for the first snowfall in the season 2008/09, the dominance of short range fluctuations might be explained by small scale bare earth terrain filling (Figure 5d). For example, this first snowfall had the largest magnitude $\gamma$ that was observed during the whole accumulation season, which points to the effect of bare earth terrain. This explanation might also be valid for the second homogeneous snowfall, since the NW storm in between was able to erode most of the upper area in this slope. However, the magnitude $\gamma$ was substantially lower, which indicates the possibility that some small scale depression remained filled with snow. This interpretation is consistent with visual observations.

[24] Confirming the effect of bare earth terrain, large $\gamma$ values were obtained for the first snowfall in the season $2009 / 10$ as well. Based on wind data from the AWS and on the patterns of snow depth distribution (pronounced accumulation zones) this first snowfall revealed typical characteristics of a NW storm, however falling on bare ground. This explains the longer break distances $(11 \mathrm{~m})$ and lower $D_{s}$ values (2.51) in comparison to the first homogeneous snowfall during low wind speeds the year before $\left(5 \mathrm{~m}, D_{s}\right.$ $=2.67$ ). Lower break distances and larger $D_{s}$ values in comparison with other NW storms reveal the influence of the bare earth terrain.

\subsubsection{Absolute Snow Depth}

[25] The development of short-range $D_{s}$ and the break distance $L$ of the absolute snow depth is shown in Figure 7. An increase in break distance after NW storms (marked with arrows) is clear (14-20 m). Similar to the development of snow depth change, the maximum was reached at the 
a
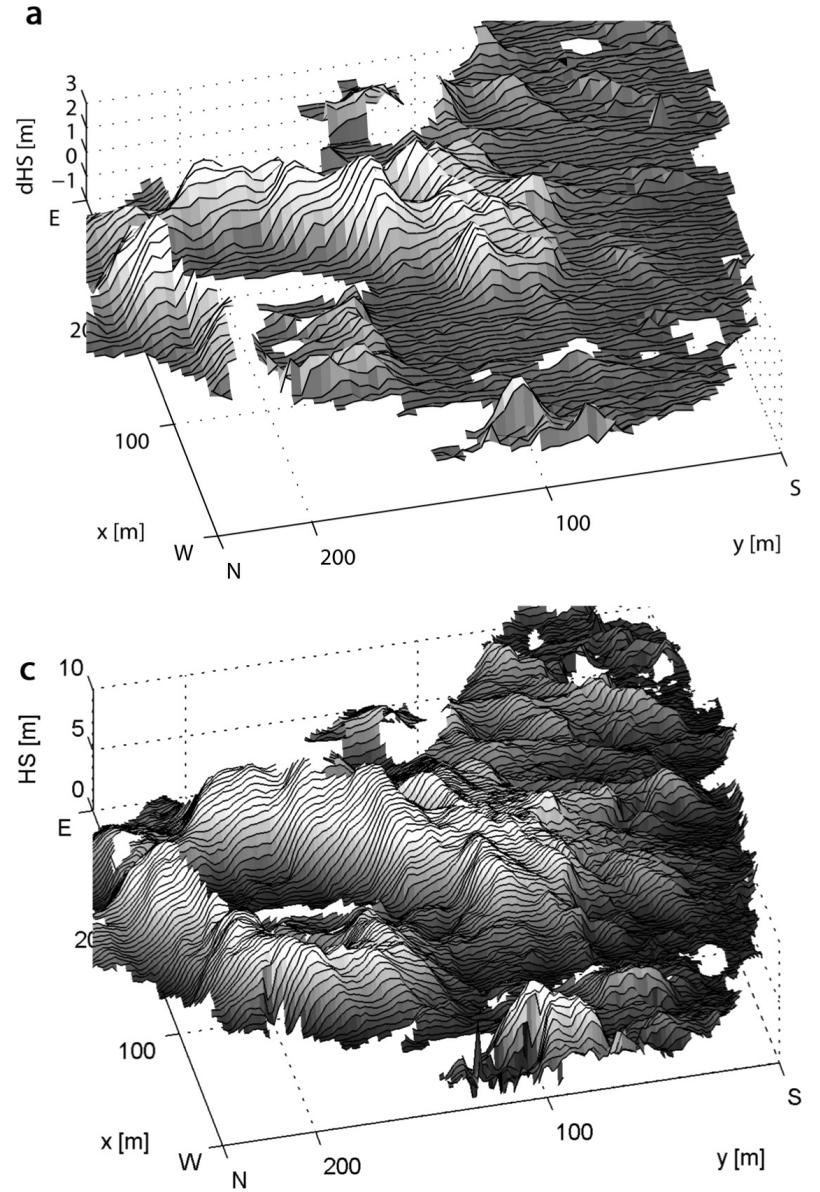

b
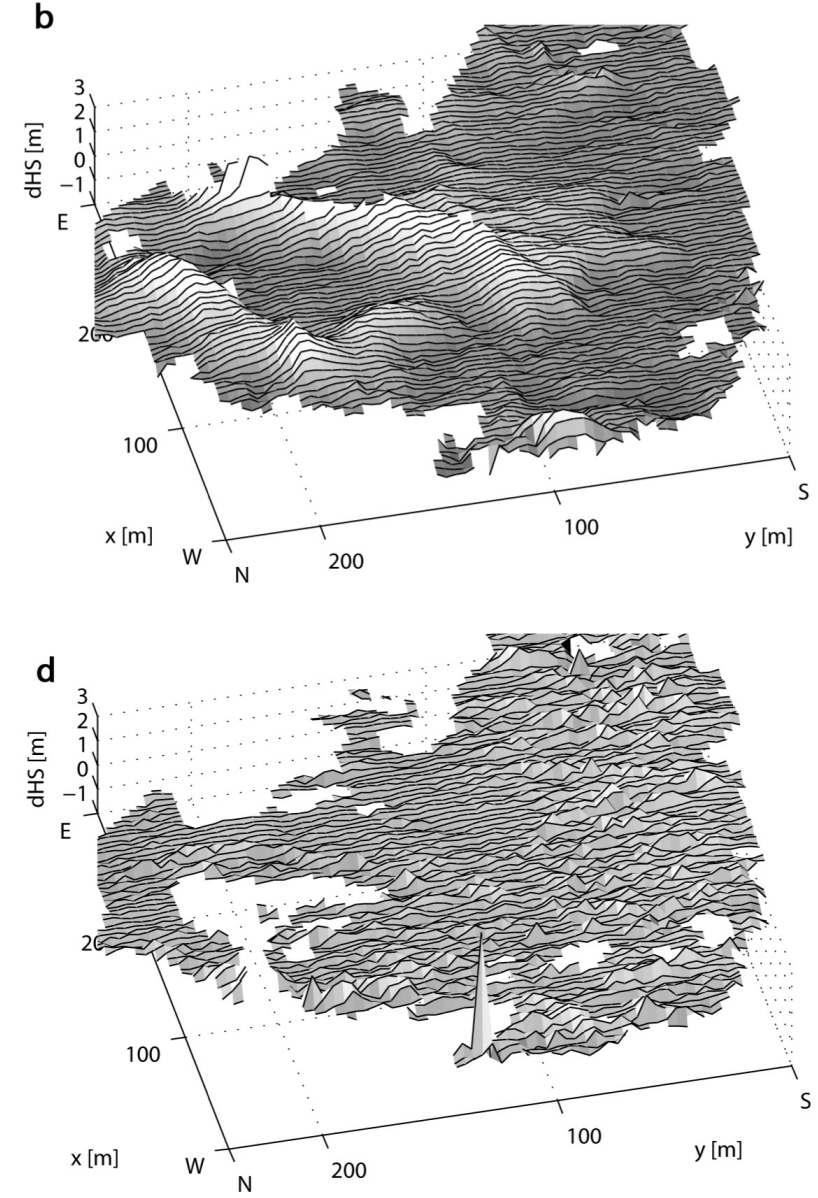

Figure 5. Change in snow depth (dHS) during (a) the first NW storm and (b) the last NW storm in 2008/09. (d) An example of a snowfall during low wind speeds and also the first snowfall in 2008/09. (c) The distribution of snow depth (HS) at the end of the accumulation season in 2008/09.

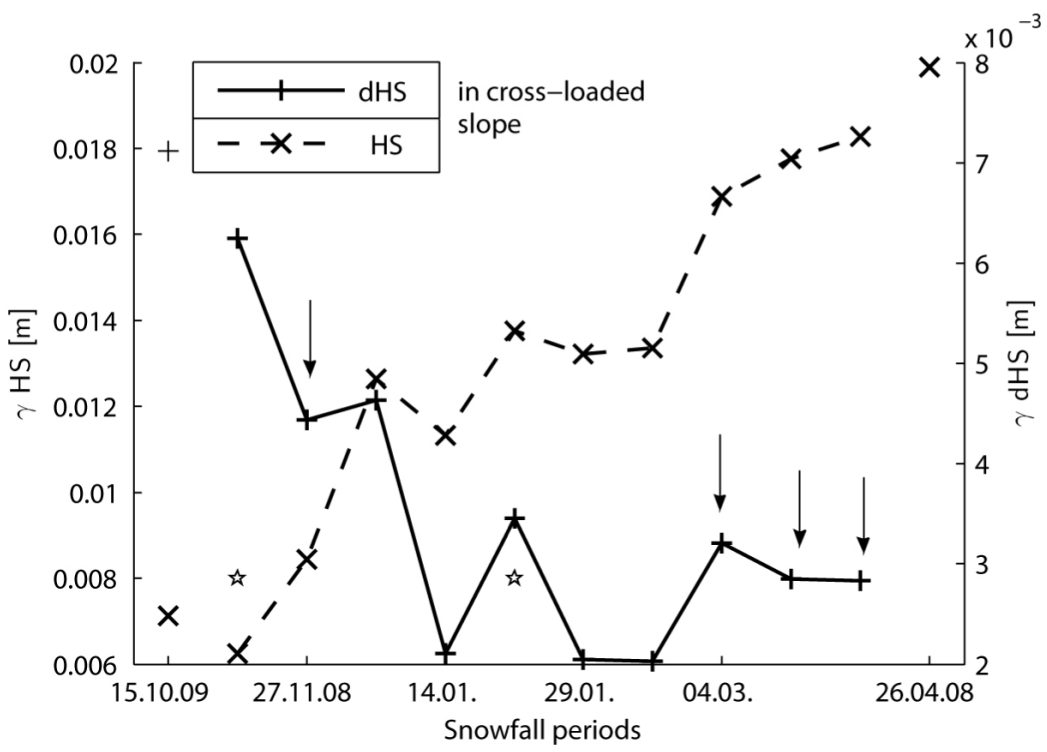

Figure 6. Temporal development of $\gamma$ determined for snow depth (HS) and snow depth change (dHS) during the winter 2008/09 in the cross-loaded slope. For comparison, parameters for the first snowfall in 2009/10 and $\gamma$ for $\mathrm{HS}_{\max }$ in 2008 is plotted without connective lines. NW storms are marked with an arrow and homogeneous loading with a star. 
end of the accumulation. However, this value was much smaller than for snow depth change (37 m, Figure 4) and more comparable to the first NW storm $(20 \mathrm{~m})$. This finding confirms the observation determined with the correlation coefficients in part 1 that the snow depth distribution at the end of the accumulation season inherits much or most of the characteristics of the first NW storm. This similarity is also shown in Figure 5: whereas both pronounced accumulation zones were homogeneously structured in the last NW storm (Figure 5b), the structure of the first NW storm (Figure 5a), with many submaxima, is still visible at the end of the accumulation season (Figure $5 \mathrm{c}$ ).

[26] The fractal dimension $D_{s}$ decreased, especially after NW storms (2.66-2.27). During these storms both accumulation zones became more and more pronounced. This may explain the increasing dominance of long-range fluctuation (before the scale break), which results in decreasing $D_{s}$ values.

[27] The ordinal intercept $\gamma$ increased during the season (Figure 6) after NW storms, similarly to the development of the overall variance shown in part 1 . The decrease in $D_{s}$ values at the same time implies a trend to more long-range dominated fluctuations and results together with the increasing $\gamma$ in a larger variance for all distances. Indeed, the variance is also dependent on the fractal dimension after the scale break, but values were comparable during the season.

[28] For comparison, values for $\mathrm{HS}_{\max }$ the year before are plotted in Figures 6 and 7, which point to the similarity between both years. Differences in time development are larger than the differences between two years at the end of the accumulation season. At the end of February, only one NW storm was observed. The increase in break distance and decrease in $D_{s}$ at the end of the accumulation season indicate that the last three NW storms could influence the spatial structure of snow depth substantially. In comparison, the periods between the first and the three last NW storms do not alter the structure of snow depth to the same degree.
These periods were SE storms without precipitation or snowfall during low wind speeds (see also part 1). Hence, snow depth structure actually inherited the characteristics of NW storms with lower $D_{s}$ and longer break distances. This indicates that the development of snow depth does not converge to a somehow predefined status at the end of the accumulation season, and that the interannual consistency of snow depth in this area is highly dependent on the frequency of NW storms in one accumulation season.

\subsubsection{Time Development in Lee Slope}

3.1.3.1. Changes in Snow Depth

[29] The differences between the lee and the crossloaded slope mentioned previously for $\mathrm{HS}_{\max }$ in Figure 2 were also seen for snow depth change during each individual snowfall, i.e., lower break distances (up to $8 \mathrm{~m}$ ), substantially larger fractal dimensions before (between 2.7 and 2.8) and after the scale break (2.9) and larger ordinal intercept $\gamma$. This indicates a rough, nonpersistent structure. A significant time development could only be observed for the ordinal intercept $\gamma$ (Figure 8), which decreases similarly as in the cross-loaded slope during NW storms. Observed differences between the cross-loaded slope and lee slope persist during the accumulation season, at least for NW storms. The exceptions to this are snowfall periods during low wind speeds in the cross-loaded slope. In those periods the fractal parameters are very similar in both areas with short break distances and large $D_{s}$ values. In brief, depositions during low wind speeds appear to reveal a typical region-independent characteristic. For the cross-loaded slope, we explained short break distances and large fractal dimensions with the influence of bare earth terrain even for the second snowfall, since NW storms were able to erode a large part of the snow fallen before, but no substantial erosion during storms was recorded in the lee slope. However, the transect description in part 1 revealed that the picture of smoothing surfaces and filling small scale depressions was partly wrong and some small scale terrain features could

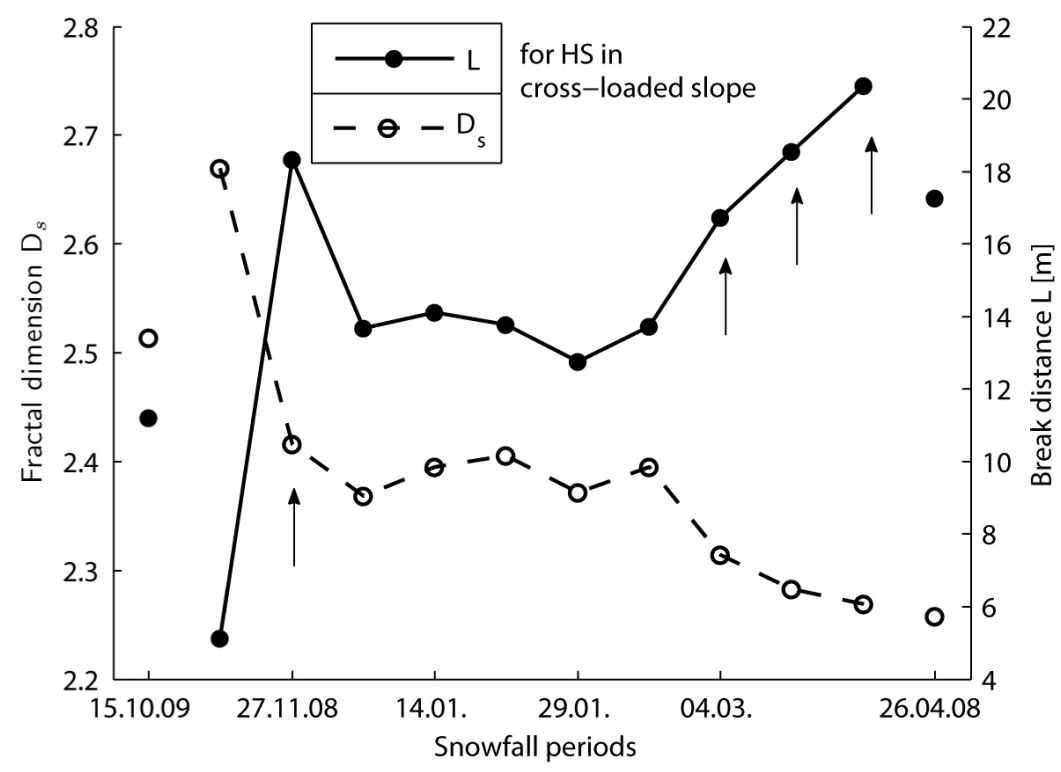

Figure 7. Temporal development of break distance $L$ and $D_{s}$ determined for snow depth during the winter 2008/09 in the cross-loaded slope. For comparison, parameters for the first snowfall in 2009/10 and for $\mathrm{HS}_{\max }$ in 2008 are plotted without connective lines. NW storms are marked with an arrow. 


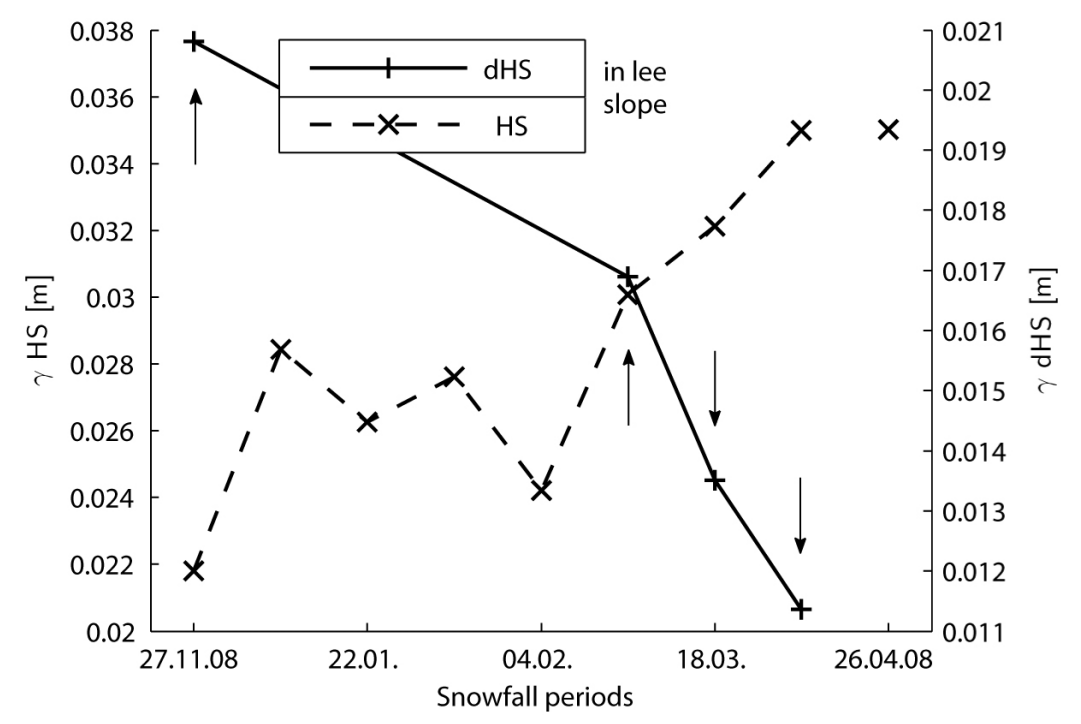

Figure 8. Temporal development of $\gamma$ determined for snow depth (HS) and snow depth change (dHS) during the winter 2008/09 in the lee slope. For comparison, $\gamma$ for $\mathrm{HS}_{\max }$ in 2008 is plotted without connective lines. NW storms are marked with an arrow.

survive the full accumulation season. In part 1 a relation of that observation to lower wind speeds was suggested. Furthermore, no increase in break distance with time could be observed in the lee slope, which is an additional indication that some terrain features were not altered to the same degree as in the cross-loaded slope. In addition to the effect of small scale terrain, small random eddies in wind flow developing in the lee slope might be a reason for the spatially less persistent deposition structure.

[30] Similarly, Trujillo et al. [2007, 2009] found shorter break distances in less wind dominated regions. They related shorter break distances in areas with lower wind speeds to existing vegetation height due to similar scaling behavior. Without disagreeing on the influence of vegetation, we could observe a relation of shorter break distances and lower wind speeds independent of vegetation since in our area the influence of vegetation can be neglected. However, Trujillo et al. [2009] found in their less wind dominated and forested area before the observed scale break a larger persistent structure in comparison to an adjacent wind dominated area, which is contrary to our observations for low wind speeds: low wind speeds without vegetation may be characterized by an antipersistent structure, while interception of trees may counteract that observation at small scales.

[31] A simpler explanation for the differences between cross-loaded slope and lee slope can be found in the larger errors of the scanner due to the longer distances to the scan position for the lee slope. More noise could result in the observed larger $D$ values. The larger footprint of the laser beam as well as the coarser resolution of the point cloud delivered should have an opposite influence. For one period the same situation could be measured from a position much close to the area of interest (Figure 1). All characteristic differences, i.e., larger fractal dimensions, shorter break distances and larger ordinal intercepts can be reproduced from this more reliable data set. The difference in break distance was less than $1 \mathrm{~m}$, in $D_{s}$ less than 0.1 , and in $D_{l}$ less than 0.01 . All differences are in the range of the intra-annual variation observed in that slope, but much smaller than the differences to other areas. In brief, the influences articulated in section 2 cannot be neglected but the characteristic differences could be reproduced and can be interpreted as natural instead of an artifact.

\subsubsection{Absolute Snow Depth}

[32] Similar temporal developments of fractal parameters for snow depth as in the cross-loaded slope were obtained. These included decreasing short-range fractal dimension (2.65 to 2.5), time-independent long-range fractal dimension, increasing ordinal intercept and a consistency in those parameters for $\mathrm{HS}_{\max }$ of different years (Figures 8 and 9). However, no increase in break distance could be observed (Figure 9).

\subsubsection{Time Development in Windward Slope}

[33] In the wind dominated windward slope increasing break distances for snow depth change (12-28 m) were observed. This supports the relation of larger wind speeds leading to larger scale breaks, although the change in wind direction between the slopes is another potential cause for the larger scale break. The increase of scale break distances during the accumulation season supports the hypothesis that in areas with larger wind speeds bare earth terrain can be altered to a larger degree.

[34] For snow depth an increase in break distance was observed at a lower level in comparison to snow depth change. These findings are consistent with the observations in the cross-loaded slope. Accordingly, break distances found for $\mathrm{HS}_{\max }(14 \mathrm{~m})$ were most similar to those of the first NW storm, which shows the dominance of the first storm also in this slope. The windward slope showed the same influence of time on the fractal parameters as already seen on the cross-loaded slope, including decreases in $D_{s}$ and increases in $\gamma$ with time and no apparent influence of time on $D_{l}$.

\subsection{Directional Variograms}

[35] As before, we describe the directional variograms in detail for the cross-loaded slope and use the lee and 


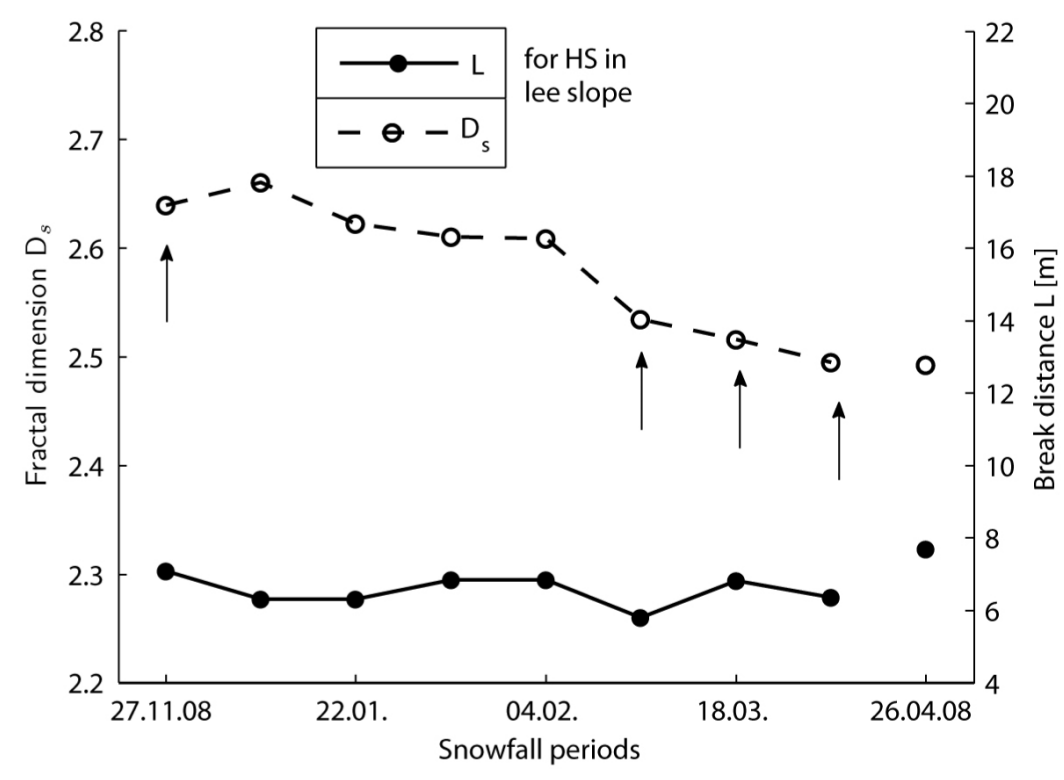

Figure 9. Temporal development of break distance and $D_{s}$ determined for snow depth during the winter 2008/09 in the lee slope. For comparison, parameters for $\mathrm{HS}_{\max }$ in 2008 are plotted without connective lines. NW storms are marked with an arrow.

windward slope to illustrate similarities and differences arising over time and from different storms.

\subsubsection{Anisotropy in Cross-Loaded Slope}

\subsubsection{Changes in Snow Depth}

[36] The anisotropy is assessed by creating directional variograms. An example is shown in Figure 10 for the last NW storm and for two selected directions. The information from the directional variograms is then collected in polar plots. During NW storms the break distances showed a substantial anisotropy as shown in the first polar plot (Figure 11).
For the last NW storm values ranged between 27 and $56 \mathrm{~m}$. The direction of the anisotropy (along the semimajor axis of an assumed ellipse) of the first storm was WNW-ESE orientated, which is mostly parallel to dominant wind direction from NW. But the anisotropy of the later storms was mostly normal to dominant wind direction, which is consistent with the orientation of the accumulation zones.

[37] Figure 12 shows anisotropy in short and long-range fractal dimension $\left(D_{s}\right.$ and $\left.D_{l}\right)$ during the first and last storm in the cross-loaded slope. The anisotropy in $D_{s}$ was not

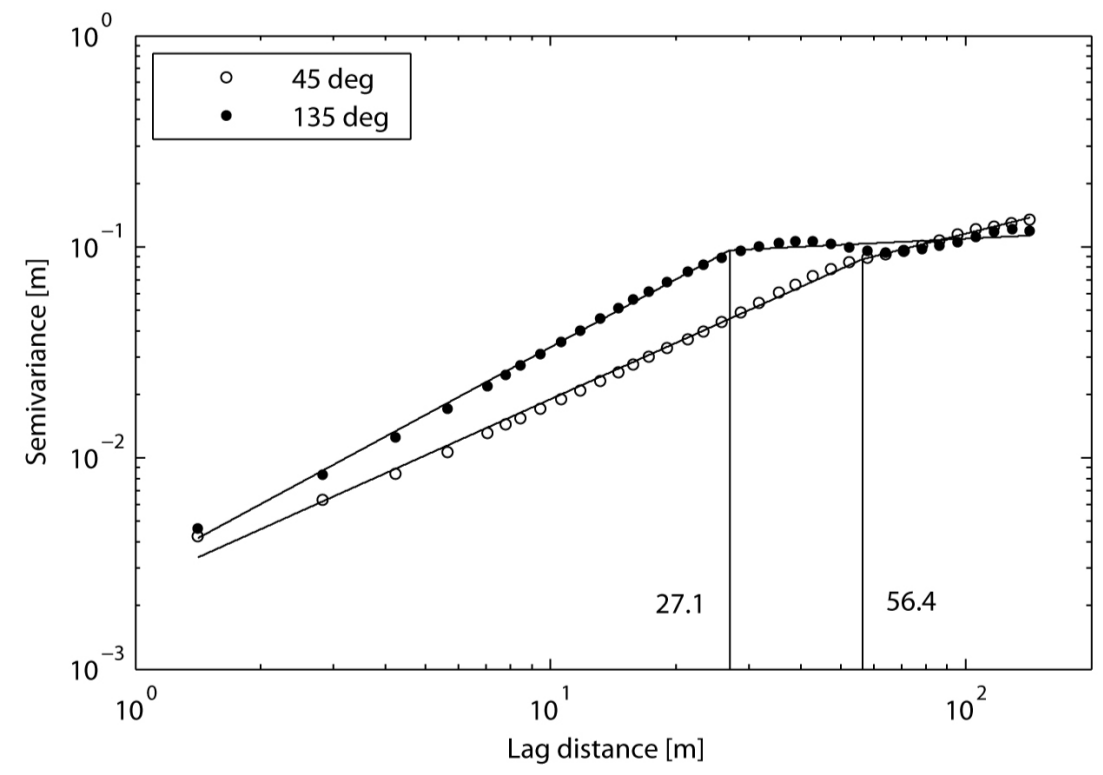

Figure 10. Directional variograms of snow depth change in the cross-loaded slope before 27 March 2009 for two selected directions. 


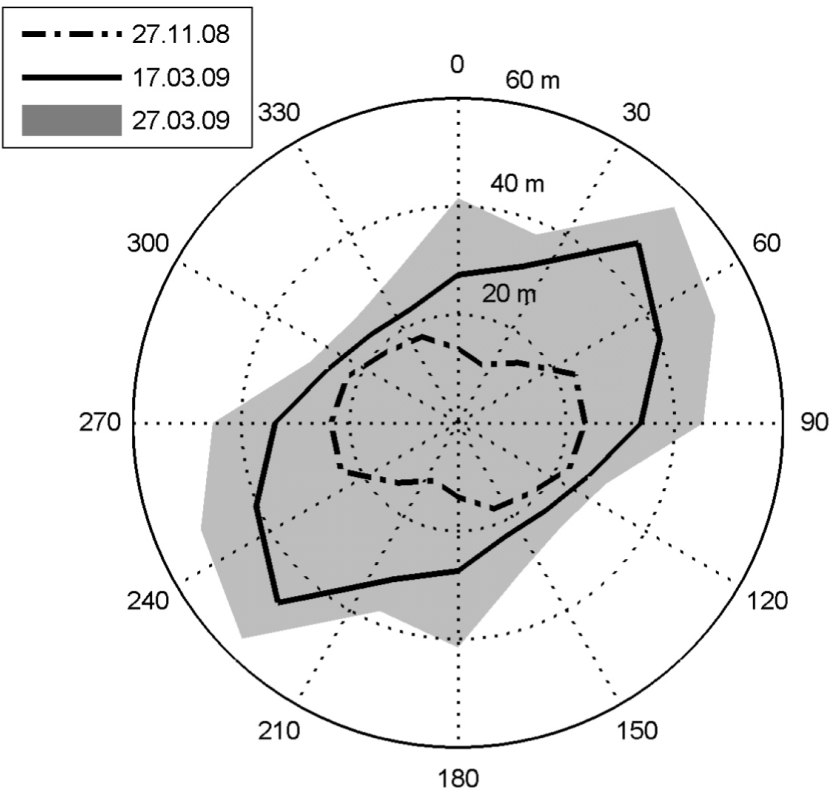

Figure 11. Scale break anisotropy of snow depth change for three selected NW storms in the crossloaded slope.

pronounced for the first storm, while for the last storm anisotropy normal to wind direction can be recognized $(2.45-$ 2.56, last NW storm). Beyond the scale break, however, a more pronounced anisotropy during all NW storms was observed (2.75-2.95, last NW storm). Normal to wind direction the structure showed a larger spatial persistence. During low wind speeds the snow depth change structure did not reveal anisotropy in $D_{l}$ (not shown).

[38] In Figure 13 the anisotropy of the ordinal intercept $\gamma$ is shown in the cross-loaded slope. A larger magnitude of the roughness which was described with $D_{s}$ was observed parallel to dominant wind direction. While values were decreasing with time (as mentioned above), the anisotropy remained similar.

\subsubsection{Absolute Snow Depth}

[39] For the scale break anisotropy, a less pronounced shift in direction was observed compared to snow depth change during NW storms. At the end of the accumulation season the direction was normal to dominant wind direction (2.60-2.91).

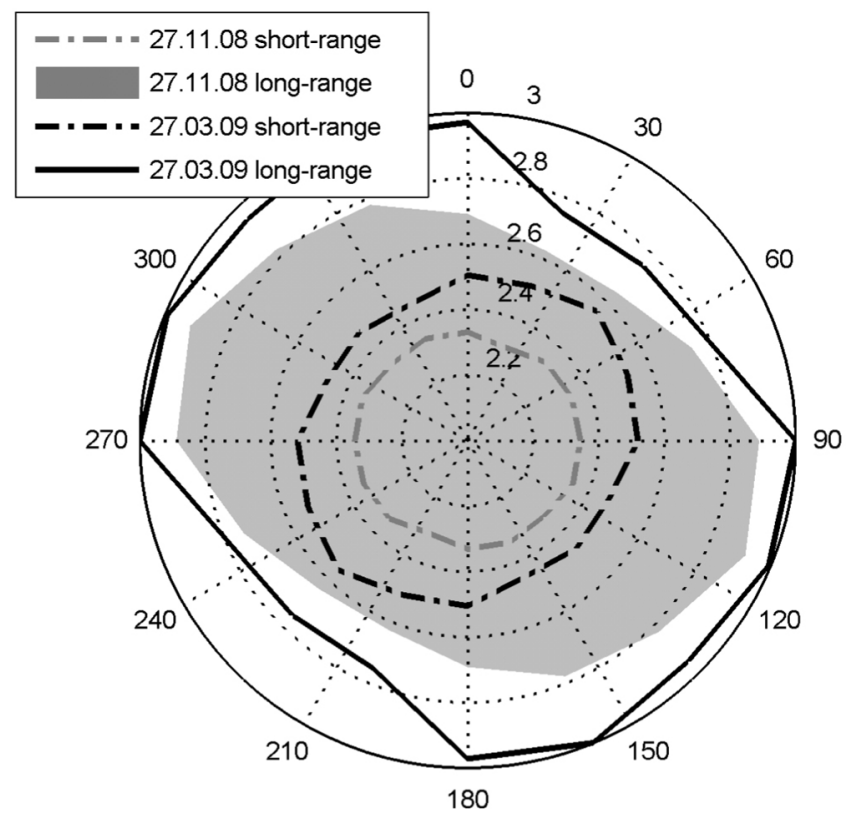

Figure 12. Fractal dimension anisotropy of snow depth change for two selected NW storms in the cross-loaded slope. 


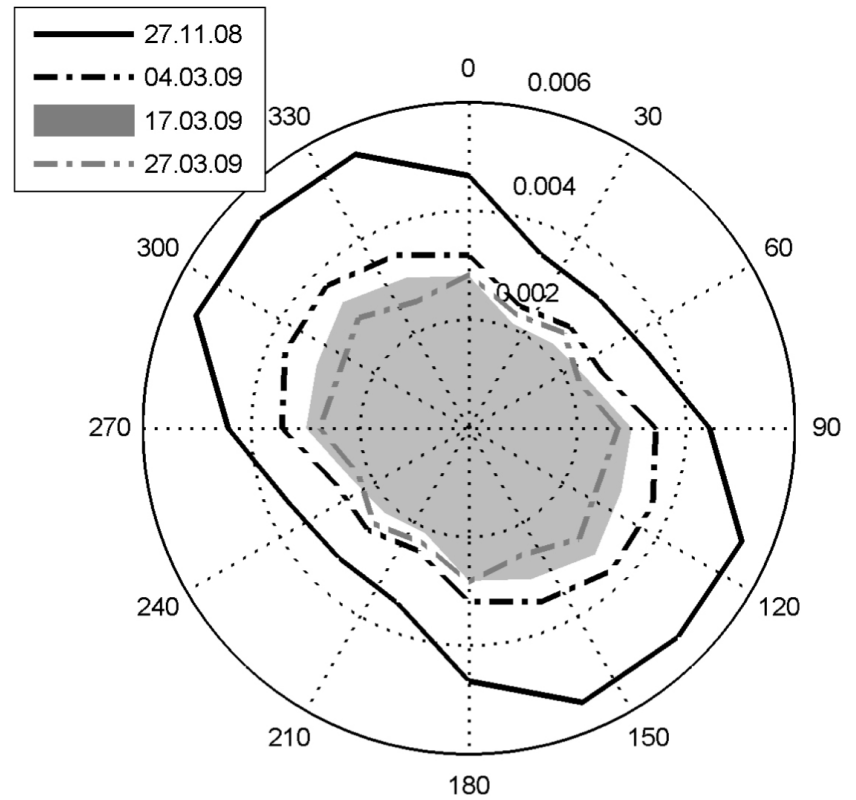

Figure 13. Ordinal intercept $\gamma$ anisotropy of snow depth change for all NW storms in the cross-loaded slope.

[40] After the last three NW storms a small anisotropy in $D_{s}$ can be observed, also normal to wind direction. This finding is consistent with Deems et al. [2006], but somewhat less pronounced. A pronounced anisotropy in $D_{l}$ was observed throughout the accumulation season, which was along dominant wind direction and again similar to snow depth change during NW storms. The relation to dominant wind direction was also found by Deems et al. [2006] and Trujillo et al. [2007] for wind dominated areas. Thus, it appears that the anisotropy of $D_{l}$, determined for example for snow depth at the end of the accumulation season, is a good indicator for dominant wind direction at the slope scale.

\subsubsection{Summary}

[41] A typical relation to wind direction could be observed both for snow depth and snow depth change for most of the measured time steps. Maximum values of $D_{l}$ and $\gamma$ were orientated along dominant wind direction. The scale break, however, was typically normal to dominant wind direction, especially at the end of the accumulation season. In comparison, Trujillo et al. [2007] found longer break distances along the dominant wind direction for snow depth at the end of the accumulation season for two wind dominated regions. Presumably, in that case, vegetation and other point obstacles protruding out of the snow surface caused snow accumulation downstream, which are longer in the wind direction than undisturbed deposition. Only for snow depth change during the first NW storm observed in our study a similar relation was found (Figure 11). This finding suggests that snow depth change during this first storm was similarly influenced by point obstacles not already covered by snow.

\subsubsection{Anisotropy in Lee Slope}

[42] We did not find a good fit to snow depth change data from the lee slope using directional variograms and equation (2). We suspect that this is a result of data quality due to the longer distance of that area to the scan position, the lower signal-to-noise ratio in comparison to snow depth, and the lower number of point pairs in comparison to the omnidirectional variograms for the same slope. We therefore report only anisotropies determined for snow depth for the lee slope, for which reliable fits could be achieved (Figure 14).

[43] The behavior of anisotropies seen on the crossloaded slope was also consistently observed on the lee slope throughout the accumulation season. The scale break anisotropy was aligned in NW-SE direction (7-9 m, $\mathrm{HS}_{\max }$ 2009, see Figure 14), while anisotropy in $D_{l}(2.77-2.91$, $\left.\mathrm{HS}_{\max } 2009\right)$ and in $\gamma$ was normal to that direction. $D_{s}$ did not show a pronounced anisotropy. The uncertainty in the determination of a dominant wind direction makes it impossible to fully explain the anisotropies by the wind directions. The weather station at the bottom of that slope (see Figure 1) as well as some sporadic drift observations indicate that at least in the lower part of that slope the wind was blowing from SW during the typical NW storms. These relation would be consistent with the relation found in the cross-loaded slope, where wind direction is known with a higher degree of certainty.

\subsubsection{Anisotropy in Windward Slope}

[44] Anisotropies were found for many parameters. Referencing to wind direction was difficult due to uncertainty in the dominant wind direction. Also, the typical perpendicular and parallel direction of anisotropies mentioned for the two other slopes could not be found, in particular for snow depth at the end of the accumulation season. We suggest that this is the result of two or more dominating situations on the snow depth structure. Additional to NW storms, the relatively large influence of the SE storms in this slope was discussed in part 1. 


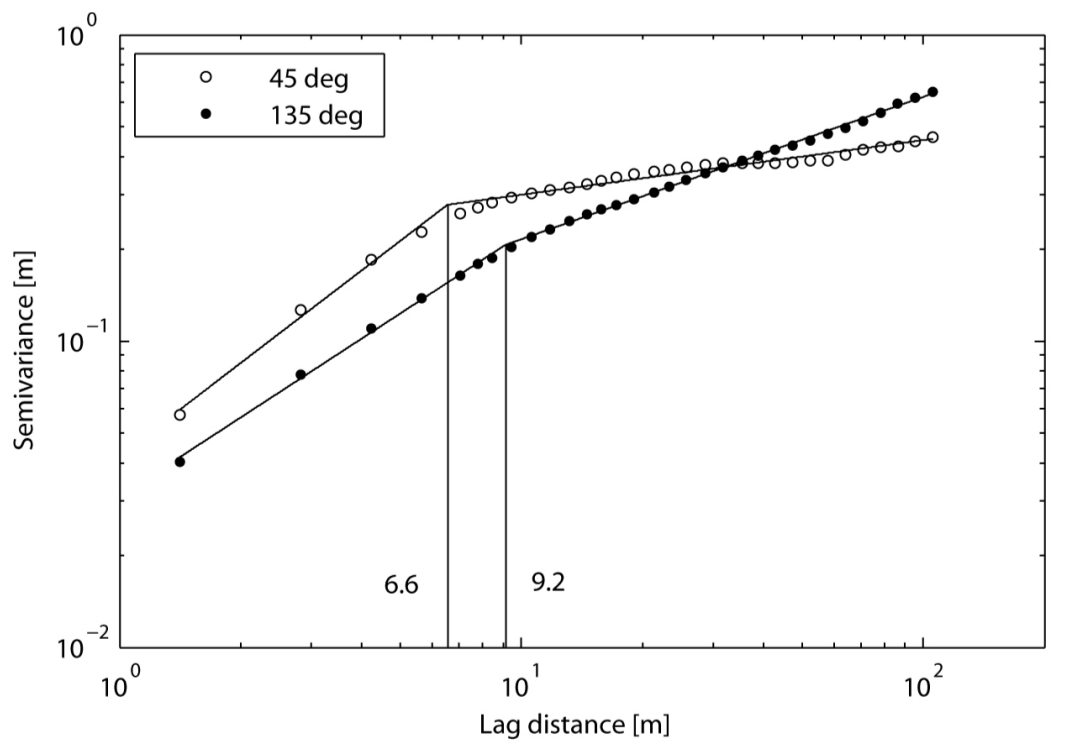

Figure 14. Directional variograms for $\mathrm{HS}_{\max }$ in 2009 in the lee slope for two selected directions.

\section{Conclusion}

[45] Fractal modeling of surface roughness and structure has historically helped to formulate general laws for complicated observations. The complex features of snow depth distribution and their changes in time in alpine terrain as described in part 1 are a typical field for applying such fractal modeling. We therefore attempted to analyze the scaling behavior of snow depth and snow depth changes for three distinct subareas in the Wannengrat catchment in SE Switzerland. This is an alpine site with no vegetation.

[46] In part 1 of this paper we showed that the snow depth development is predominantly shaped by northwest storms which lead to a similar snow depth distribution at maximum accumulation. In this part, we have shown that fractal parameters are able to distinguish snow depth structure in wind-protected and wind-exposed areas and the structure of snow depth change during more and less windinfluenced snowfall periods. In the two wind-exposed subareas the development of snow depth change after NW storms can be summarized with a tendency toward larger break distances in the course of the winter and toward smaller intercept $\gamma$ and fractal dimension $D$. While we only analyzed three rather small subareas in a particular catchment, we expect these trends to be generally valid, which remains to be shown by subsequent studies, however.

[47] While former studies tried to relate the observed scale break to vegetation influence, we interpret the scale break in a different way since vegetation influence can be neglected in our study area. It can be interpreted as the roughness scale of bare earth terrain which is modified by snow fall and hence dominantly influences snow deposition at a slope scale. At distances larger than the scale break the signal of bare earth terrain persists. These interpretations are consistent with the visual observation that small scale variations in topography get smoother during the winter but that the roughness scale that produces the dominant snow drifts (i.e., the break distance) remain intact. This is a prerequisite to obtain persistent characteristics of NW storms throughout an accumulation season described in part 1.
[48] An increase in break distance can be seen as a result of successive smoothing of bare earth terrain, which allows processes as saltation and suspension to act at a slightly increasing scale ( 20 to $40 \mathrm{~m}$ ). A trend toward smaller intercept $\gamma$ suggests that small scale roughness is reduced, similar to the decrease of fractal dimension $D$.

[49] The snow depth on the (nominal) lee slope has larger intercept $\gamma$, larger $D$, and a smaller break distance than the cross-loaded slope. The break distance does not change noticeably during the winter. We suggest that if winds are low, bare earth surface smoothing is restricted to the filling of depressions (small scale, i.e., below the break distance).

[50] The time development shows the dominance of NW storms on the snow depth structure at the end of the accumulation season. Other events as SE storms without precipitation and snowfall during low wind speed were not able to influence snow depth structure equivalently. This dominance of NW storms was already quantified in part 1 with good correlations between snow depth change due to NW storms and the maximum snow depth data. As a result of correlation coefficients up to $r=0.97$ between $\mathrm{HS}_{\max }$ of two different winters it was proposed in part 1 that snow depth development converge to a similar final snow distribution. However, time development of fractal parameters suggests that even at the end of the accumulation season snow depth structure was highly altered by individual NW storms. Hence, the interannual consistency observed between two years might be strongly dependent on the frequency of dominant NW storms in an accumulation season.

[51] Up to now, three areas, one in this study and two areas investigated by Deems et al. [2008], show a large interannual consistency. Future work will address the question of whether or not years or areas with less interannual consistency can be found in alpine terrain and if reasons for those differences can be found, e.g., the dominance of not only one precipitation event.

[52] A large avalanche was observed in the lee slope (see part 1). The observed snow depth structure (small break distance) might favor fracture propagation over large distances 
because the small break distance shows that the snow cover uniformly follows the terrain at larger scales. More studies are needed in areas where large avalanches were recorded to establish a relationship between snow depth structure and the occurrence of large avalanches.

[53] Future work will involve snow depth scaling investigation for larger areas and all possible subareas such as steep rock walls and other surface features. An automatic procedure to generate consistent subareas using clustering will be attempted. The ultimate goal is to describe mean snow depth and snow depth variations based on simple terrain parameters and overall precipitation information. This would be a major step forward in the field, in which the basic question of "how much snow is on the mountain, where, when and why" is currently unanswered. Our research will complete our picture of the Earth's surface roughness without snow [e.g., Mark and Aronson, 1984; Perron et al., 2008; Abedini and Shaghaghian, 2009] and with snow. In particular, we want to characterize snow surface roughness from the scale of the individual snow grain [Manes et al., 2008 ] to the scale of snow drifts investigated here.

[54] This work has shown that it may be possible to build a coherent fractal description of snow distribution in alpine terrain based on terrain models and knowledge of prevailing winds. This would be an extremely valuable tool for hazard warning, remote sensing and mountain hydrology.

[55] Acknowledgments. This work has partially been funded by the Swiss National Science Foundation and the Swiss Federal Office of the Environment. We acknowledge the valuable comments provided by Andrew Clifton and Christine Groot Zwaaftink. We are very grateful to our colleagues at SLF who helped during the field campaigns, especially Thomas Grünewald, Luca Egli, Rebecca Mott, and Yvonne Schaub. The manuscript has been improved significantly by the work of John Selker, Anne Nolin, Ethan Gutmann, and one anonymous reviewer.

\section{References}

Abedini, M., and M. Shaghaghian (2009), Exploring scaling laws in surface topography, Chaos Solitons Fractals, 42(4), 2373-2383.

Anderton, S., S. White, and B. Alvera (2004), Evaluation of spatial variability in snow water equivalent for a high mountain catchment, Hydrol. Processes, 18(3), 435-453.

Arnold, N. S., and W. G. Rees (2003), Self-similarity in glacier surface characteristics, J. Glaciol., 49(8), 547-554, doi:10.3189/172756503781 830368.

Burrough, P. (1981), Fractal dimensions of landscapes and other environmental data, Nature, 294(5838), 240-242.

Burrough, P. (1993), Fractals and geostatistical methods in landscape studies, in Fractals in Geography, edited by N. Lam and L. De Cola, pp. 87 121, PTR Prentice Hall, Englewood Cliffs, NJ.

Deems, J., S. Fassnacht, and K. Elder (2006), Fractal distribution of snow depth from LiDAR data, J. Hydrometeorol., 7(2), 285-297.

Deems, J., S. Fassnacht, and K. Elder (2008), Interannual consistency in fractal snow depth patterns at two Colorado mountain sites, J. Hydrometeorol., 9(5), 977-988.

Fassnacht, S., M. Williams, and M. Corrao (2009), Changes in the surface roughness of snow from millimetre to metre scales, Ecolog. Complex., $6(3), 221-229$, special section: Fractal Modeling and Scaling in Natural Systems.
Goodchild, M., and D. Mark (1987), Review article: The fractal nature of geographic phenomena, Ann. Assoc. Am. Geograph., 77(2), 265-278.

Grünewald, T., M. Schirmer, R. Mott, and M. Lehning (2010), Spatial and temporal variability of snow depth and SWE in a small mountain catchment, Cryosphere, 4, 215-225.

Klinkenberg, B., and M. Goodchild (1992), The fractal properties of topography: a comparison of methods, Earth Surf. Processes Landforms, 17(3), 217-234.

Kuchment, L., and A. Gelfan (2001), Statistical self-similarity of spatial variations of snow cover: Verification of the hypothesis and application in the snowmelt runoff generation models, Hydrol. Processes, 15(18), 3343-3355.

Lam, N., and L. De Cola (1993), Introduction to fractals in geography, in Fractals in Geography, edited by N. Lam and L. De Cola, pp. 3-22, PTR Prentice Hall, Englewood Cliffs, NJ.

Lehning, M., P. Bartelt, B. Brown, T. Russi, U. Stöckli, and M. Zimmerli (1999), Snowpack model calculations for avalanche warning based upon a network of weather and snow stations, Cold Regions Sci. Technol., 30(1-3), 145-157.

Mandelbrot, B. (1977), Fractals: Form, Chance and Dimension, 365 pp., W.H. Freeman and Company, San Francisco, CA.

Mandelbrot, B. (1982), The Fractal Geometry of Nature, 468 pp., W.H. Freeman and Company, New York.

Manes, C., M. Guala, H. Löwe, S. Bartlett, L. Egli, and M. Lehning (2008), Statistical properties of fresh snow roughness, Water Resour. Res., 44(11), W11407, doi:10.1029/2007WR006689.

Mark, D., and P. Aronson (1984), Scale-dependent fractal dimensions of topographic surfaces: An empirical investigation, with applications in geomorphology and computer mapping, Math. Geol., 16(7), 671-683.

Mott, R., M. Schirmer, M. Bavay, T. Grünewald, and M. Lehning (2010), Understanding snow-transport processes shaping the mountain snowcover, Cryosphere, 4(4), 545-559.

Pachepsky, Y., and J. Ritchie (1998), Seasonal changes in fractal landscape surface roughness estimated from airborne laser altimetry data, Int. J. Remote Sensing, 19(13), 2509-2516.

Pentland, A. (1984), Fractal-based description of natural scenes, IEEE Trans. Pattern Anal. Mach. Intel., 6, 661-674.

Perron, J., J. Kirchner, and W. Dietrich (2008), Spectral signatures of characteristic spatial scales and nonfractal structure in landscapes, J. Geophys. Res., 113, F04003, doi:10.1029/2007JF000866.

Schirmer, M., V. Wirz, A. Clifton, and M. Lehning (2011), Persistence in intra-annual snow depth distribution: 1. Measurements and topographic control, Water Resour. Res., 47, W09516, doi:10.1029/2010WR009426.

Shook, K., and D. Gray (1996), Small-scale spatial structure of shallow snowcovers, Hydrol. Processes, 10(10), 1283-1292.

Sun, W., G. Xu, P. Gong, and S. Liang (2006), Fractal analysis of remotely sensed images: A review of methods and applications, Int. J. Remote Sensing, 27(21-22), 4963-4990.

Trujillo, E., J. Ramírez, and K. Elder (2007), Topographic, meteorologic, and canopy controls on the scaling characteristics of the spatial distribution of snow depth fields, Water Resour. Res., 43(7), W07409, doi:10. 1029/2006WR005317

Trujillo, E., J. Ramírez, and K. Elder (2009), Scaling properties and spatial organization of snow depth fields in sub-alpine forest and alpine tundra, Hydrol. Processes, 23(11), 1575-1590.

Webster, R., and M. Oliver (2007), Geostatistics for Environmental Scientists, Wiley, New York.

Weng, Q. (2003), Fractal analysis of satellite-detected urban heat island effect, Photogramm. Eng. Remote Sensing, 69(5), 555-566.

$\mathrm{Xu}$, T., I. D. Moore, and J. C. Gallant (1993), Fractals, fractal dimensions and landscapes-A review, Geomorphology, 8(4), 245-262, doi:10.1016/0169-555X(93)90022-T.

M. Lehning and M. Schirmer, WSL Institute for Snow and Avalanche Research SLF, Flüelastrasse 11, CH-7260 Davos, Switzerland. (lehning@) slf.ch; schirmer@slf.ch) 